\title{
Curso de Graduação em Biblioteconomia da UFRN: proposta metodológica para sua reformulação ${ }^{1}$
}

\author{
Pedro Alves Barbosa Neto \\ Doutor em Ciência da Informação pela Universidade Federal de Minas Gerais (UFMG) \\ Professor Adjunto do Departamento de Ciência da Informação da Universidade Federal do Rio \\ Grande do Norte (UFRN). \\ E-mail: pedrocorone@hotmail.com \\ Luciana Moreira Carvalho \\ Doutora em Ciência da Informação pela Universidade do Porto - Portugal (UP) \\ Professora Associada do Departamento de Ciência da Informação da Universidade Federal do Rio \\ Grande do Norte (UFRN). \\ E-mail: lucianamoreiraufrn@gmail.com \\ Jacqueline de Araújo Cunha \\ Doutoranda em Ciência da Informação pela Universidade Federal do Rio de Janeiro (UFRJ-IBICT) \\ Professora Adjunta do Departamento de Ciência da Informação da Universidade Federal do Rio \\ Grande do Norte (UFRN). \\ E-mail: jacquelinecunh@gmail.com
}

\begin{abstract}
RESUMO:
No presente trabalho objetivou-se, de forma geral, descrever os processos reflexivos empreendidos pelo Núcleo Docente Estruturante (NDE) do Curso de Biblioteconomia da Universidade Federal do Rio Grande do Norte (UFRN), acerca da reformulação do Projeto Pedagógico do Curso (PPC), especificamente sobre a estrutura curricular. Como suporte para as reflexões foi feito um resgate histórico da formação do Bibliotecário no Brasil, a partir da análise descritiva das estruturas curriculares adotadas em cada contexto histórico social, vinculando-o as suas inspirações teóricas e identitárias. Em continuidade foi apresentada a formação dos currículos mínimos (1962 e 1982) para os Cursos de Biblioteconomia, e a posterior migração da perspectiva dos conteúdos para as competências e habilidades emanadas pelas Diretrizes Curriculares Nacionais (DCN). Finalmente, como resultado, foi apresentada a proposta de metodologia utilizada para reformular a estrutura curricular do Curso de Biblioteconomia da UFRN, a luz das reflexões acerca das DCN.
\end{abstract}

Palavras-chave: Reformulação curricular. Currículo Mínimo. Diretrizes Curriculares Nacionais. Graduação em Biblioteconomia. Universidade Federal do Rio Grande do Norte

\section{RESUMEN:}

En este trabajo nos propusimos, en general, describir los procesos de reflexión llevadas a cabo por el Núcleo Docente de Estructuración (NDE) del Grado en Bibliotecología de la Universidad Federal de Rio Grande do Norte, en la reformulación del Proyecto Pedagógico de Curso (PPC), específicamente sobre la estructura curricular del grado. Como apoyo a las reflexiones se hizo un estudio histórico de la formacion del Bibliotecario en Brasil, a partir del análisis descriptivas

\footnotetext{
${ }^{1}$ Este trabalho é uma produção do Grupo de Pesquisa Informação na Sociedade Contemporânea e foi apresentado durante X Encontro de Docentes de Escolas de Biblioteconomia e Ciência da Informação do MERCOSUL - EBCIM 2016
} 
de los marcos curriculares adoptados por cada contexto histórico social y suya vinculación con sus inspiraciones teóricas y de identidad. El artículo continua con la formación de las enseñanzas mínimas (1962 y 1982) para los cursos de Bibliotecología y su posterior migración desde la perspectiva del contenido de las competencias y habilidades emitidos por las Directrices Curriculares Nacionales (DCN). Por último, se presenta la metodología propuesta para formar el nuevo plan de estúdios para el Grado en Bibliotecología de la Universidad Federal de Rio Grande do Norte, desde las reflexiones sobre las DCN.

Palabras-clave: Reforma curricular. Plan de estudios mínimo. Directrices Curriculares Nacionales. Grado en Bibliotecología. Universidade Federal do Rio Grande do Norte

\section{INTRODUÇÃO}

A discussão acerca da responsabilidade da formação do bibliotecário não é recente, ela surge a partir dos debates oriundos da dinamicidade, em todos os seus aspectos, que a sociedade contemporânea está inserida. No contexto brasileiro estas discussões debutam juntamente com o século $X X$, quando surgem as primeiras escolas de Biblioteconomia.

Nesta perspectiva, sentiu-se a necessidade de empreender a reformulação do projeto pedagógico do Curso de Biblioteconomia tendo em vista o lapso temporal desde a sua última reformulação ocorrida no ano de 2007. Este processo se inseriu no bojo da necessidade de prover uma formação bibliotecária de qualidade em consonância com o atual cenário social, político e econômico, à luz do que ocorre no nível nacional, observando seu impacto local.

Trata-se de um exercício constante de auto avaliação que abarca tanto os conteúdos que compõem a estrutura curricular quanto o reflexo na inserção do egresso do Curso de Biblioteconomia da UFRN no mercado de trabalho. Análise que tem sido realizada sistematicamente através do projeto de pesquisa de Moreira (2014).

No presente trabalho objetivou-se, de forma geral, descrever os processos reflexivos empreendidos pelo Núcleo Docente Estruturante (NDE) do Curso de Biblioteconomia da UFRN, acerca da reformulação do Projeto Pedagógico do Curso (PPC), especificamente sobre a estrutura curricular.

Como suporte para as reflexões foi feito um resgate histórico da formação do Bibliotecário no Brasil, a partir da análise descritiva das estruturas curriculares 
adotadas em cada contexto histórico social, vinculando-o as suas inspirações teóricas e identitárias.

Em continuidade foi discutida a formação dos currículos mínimos (1962 e 1982) para os Cursos de Biblioteconomia, e a posterior migração da perspectiva dos conteúdos para as competências e habilidades emanadas pelas Diretrizes Curriculares Nacionais (DCN).

Finalmente, é apresentada a proposta de metodologia utilizada para reformular a estrutura curricular do Curso de Biblioteconomia da UFRN, a luz das reflexões acerca das DCN.

\section{BREVE HISTÓRICO DA FORMAÇÃO BIBLIOTECÁRIA NO BRASIL}

A formação bibliotecária no Brasil surge nos primórdios do século $X X$ para formar profissionais que atendessem a demandas internas as instituições que os criaram. Estes foram os casos emblemáticos dos cursos formalizados pela Biblioteca Nacional (BN), no Rio de Janeiro em 1911, e pelo colégio Mackenzie de São Paulo que inaugurou, em 1929, o Curso Elementar de Biblioteconomia.

Estes cursos apresentavam em suas propostas pedagógicas a reprodução de dois modelos estrangeiros. O primeiro caracterizado como sendo humanista erudito, inspirava-se no modelo europeu, notadamente o francês, da École des Chartes. Este era o modelo predominante na formação da BN. Já o segundo, caracterizado como tecnicista, foi forjado a partir do modelo norte americano, marcado fortemente pelo uso das classificações decimais na organização de acervos. Este foi o viés adotado pelo segundo curso fundado no Brasil, em São Paulo.

Estas iniciativas pioneiras serviram para formar profissionais que já atuavam em bibliotecas. Tratavam-se de verdadeiros treinamentos para profissionais, afim de qualificar os recursos humanos para atuar em bibliotecas.

Conforme nos relata Castro (2000), essas escolas geravam uma verdadeira dicotomia na Biblioteconomia brasileira, os profissionais formados em São Paulo defendiam fortemente que o bibliotecário deveria ter um perfil mais técnico, ao passo que os profissionais formados no Rio de Janeiro defendiam uma formação mais humanista, deveria ser um erudito, antes de tudo. Essa polarização pode ser observada a partir do quadro 1 abaixo: 
Quadro 1 - Primeiras disciplinas da formação do Bibliotecário no Brasil

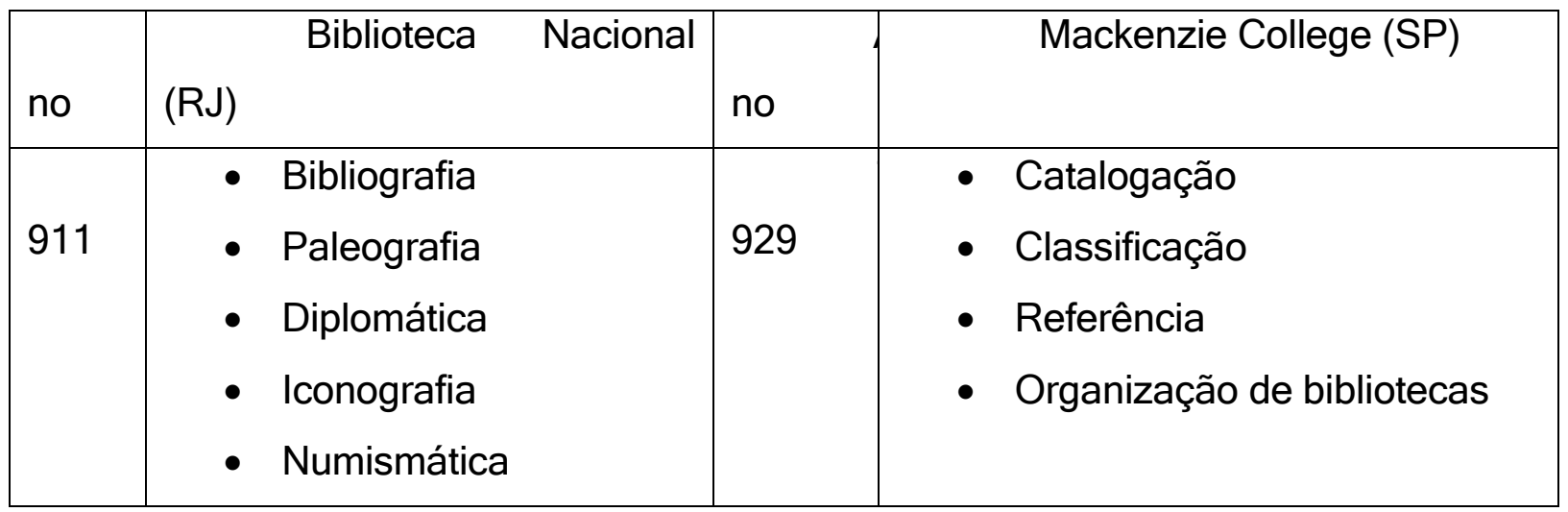

Fonte: Castro (2000)

A orientação tecnicista foi a que ganhou maior repercussão nos cursos de Biblioteconomia que surgiram nos demais estados brasileiros. No final da década de 60 já contabilizavam 18 cursos nas principais cidades do país (OLIVEIRA; CARVALHO; SOUZA, 2009).

Porém, no ano de 1962, é que a formação de bibliotecário no Brasil passa a ser de nível superior, o que aconteceu a partir da regulamentação da profissão no mesmo ano, com a Lei federal 4.084. O instrumento legal previa que o exercício da profissão estaria privativo ao Bacharel em Biblioteconomia, formado por instituição de ensino superior reconhecido pelo Ministério da Educação (MEC). Neste momento é que se estabelece o currículo mínimo do curso, padronizando a formação bibliotecária em todo território nacional e buscando, em certa medida, compatibilizar as duas vertentes: humanista e tecnicista.

De acordo com Almeida e Baptista (2013) o primeiro currículo mínimo foi elaborado por professores renomados da área na época, mas que sofreu a interferência do Conselho Federal de Educação (CFE) que teria alterado a proposta inicial dando ênfase as disciplinas de caráter humanista, o que gerou insatisfação dos docentes no país.

Esta alteração, de acordo com Russo (1966, apud OLIVEIRA; CARVALHO; SOUZA, 2009), teria sido imposta pelo fato de que o ensino da Biblioteconomia havia se tornado, no decorrer dos anos, exclusivamente técnico. Esse fenômeno teria reduzido o fazer bibliotecário a produção e reprodução de fichas e ordenação de livros em estantes. Portanto, sem participação na gestão de bibliotecas.

Várias críticas foram feitas ao currículo de 1962, a maioria denunciava tratarse de uma importação da formação estrangeira e que em nada correspondia às Rev. Inf. na Soc. Contemp., Natal, RN, v.1, n.2, jan./jun., 2017 | 
necessidades locais. Havia a percepção de que se fazia necessária a criação de um currículo que formasse profissionais capazes de refletir as técnicas e adequá-las quando necessário.

Passados 20 (vinte) anos do primeiro currículo, em 1982 foi estabelecido o segundo currículo mínimo, o qual apresentou poucas novidades, segundo Muller (1988). A nova proposta categorizou as disciplinas em três tipologias: matérias de fundamentação geral, matérias instrumentais e matérias de formação profissional (ALMEIDA; BAPTISTA, 2013).

O segundo currículo mínimo previa que a denominação das disciplinas tivesse caráter mais geral de forma a possibilitar a atualização dos conteúdos quando necessário. Nisso residiu as principais críticas que decorreram de sua implantação. Por sua característica de formação generalista, acreditava-se que o Currículo não preparava o profissional para atuar em unidades mais especializadas e também tecnicista, por não preparar o profissional para o trato com os usuários. (SOUZA, 1990).

De acordo com Souza (2001), o modelo do ensino superior brasileiro, através do currículo mínimo, findava por engessar as estruturas curriculares, no que concerne - conteúdo, acarretando a formação de profissionais desconectados das necessidades sociais de seu tempo. Na época, Souza (2001) denunciou "[...]a biblioteconomia brasileira tem permanecido alienada em seu conteúdo curricular que, de 1962 a 1982, congelou uma certa estrutura; de 1982 até agora (2000) congelou outra estrutura não muito diferente da primeira e trabalhou um conteúdo nem sempre atual e preparado para responder ao contexto social e econômico". (SOUZA, 2001, p. 8)

Na década de 1990 foi que percebeu-se de forma mais acentuada a necessidade constante de atualização do Bibliotecário. Com as novas tecnologias de informação e comunicação invadindo as bibliotecas, o imperativo por mudanças na formação do bibliotecário ficou ainda mais evidenciada, em especial com a mudança do fazer pautado no trato do documento para o fazer norteado pelo conceito de informação.

Nesta perspectiva, novas mudanças eram ensejadas para formação do novo perfil profissional, para o qual deveriam se delinear uma nova estrutura formativa. É também neste contexto, final da década de 90, que o ensino superior brasileiro passa a não mais normatizar a formação em nível de graduação através de currículos 
mínimos, mas sim de Diretrizes Curriculares Nacionais (DCN). Tal evento decorre do cenário político do país que na época vivenciava sua redemocratização com a Constituição de 1988 e aprovava sua Lei de Diretrizes e Bases (LDB) (SOUZA, 2012).

As Diretrizes Curriculares Nacionais para o ensino de Biblioteconomia foram estabelecidas pelo Parecer CNE/CES 492/2001 do Conselho Nacional de Educação/Câmara Superior de Educação. O parecer, aboliu o currículo mínimo e conferiu mais autonomia as instituições de ensino. Ele traz em sua estrutura cinco pontos de definição, a saber: perfil dos formandos, as competências e habilidades, tanto gerais quanto específicas; Conteúdos curriculares; Estágios e atividades complementares; Estrutura do curso e por fim avaliação institucional.

Sobre o perfil dos formandos, o documento enfatiza que os egressos do curso devem, dentre outras coisas, estarem preparados para atuarem em diferentes unidades de informação. Para tanto precisam desenvolver competências e habilidades as quais apresenta-se no quadro 2 a seguir:

\section{Quadro 2 - Competências e habilidades na formação do Bibliotecário}

\begin{tabular}{|c|c|}
\hline Competências gerais & Competências específicas \\
\hline $\begin{array}{l}\text { Gerar produtos a partir dos conhecimentos } \\
\text { adquiridos e divulgá-los }\end{array}$ & $\begin{array}{l}\text { Interagir e agregar valor nos processos de } \\
\text { geração, transferência e uso da informação, } \\
\text { em todo e qualquer ambiente }\end{array}$ \\
\hline Formular e executar políticas institucionais & $\begin{array}{l}\text { Criticar, investigar, propor, planejar, } \\
\text { executar e avaliar recursos e produtos de } \\
\text { informação; }\end{array}$ \\
\hline $\begin{array}{l}\text { Elaborar, coordenar, executar e avaliar } \\
\text { planos, programas e projetos }\end{array}$ & $\begin{array}{l}\text { Trabalhar com fontes de informação de } \\
\text { qualquer natureza; }\end{array}$ \\
\hline $\begin{array}{l}\text { Utilizar racionalmente os recursos } \\
\text { disponíveis }\end{array}$ & $\begin{array}{l}\text { Processar a informação registrada em } \\
\text { diferentes tipos de suporte, mediante a } \\
\text { aplicação de conhecimentos teóricos e } \\
\text { práticos de coleta, processamento, } \\
\text { armazenamento e difusão da informação; }\end{array}$ \\
\hline Desenvolver e utilizar novas tecnologias & $\begin{array}{l}\text { Realizar pesquisas relativas a produtos, } \\
\text { processamento, transferência e uso da } \\
\text { informação }\end{array}$ \\
\hline \multicolumn{2}{|l|}{$\begin{array}{l}\text { Traduzir as necessidades de indivíduos, } \\
\text { grupos e comunidades nas respectivas } \\
\text { áreas de atuação }\end{array}$} \\
\hline \multicolumn{2}{|l|}{$\begin{array}{l}\text { Desenvolver atividades profissionais } \\
\text { autônomas, de modo a orientar, dirigir, } \\
\text { assessorar, prestar consultoria, realizar } \\
\text { perícias e emitir laudos técnicos e } \\
\text { pareceres; }\end{array}$} \\
\hline $\begin{array}{l}\text { Responder a demandas sociais de } \\
\text { informação produzidas pelas } \\
\text { transformações tecnológicas que }\end{array}$ & \\
\hline
\end{tabular}

Rev. Inf. na Soc. Contemp., Natal, RN, v.1, n.2, jan./jun., 2017 | 
caracterizam o mundo contemporâneo

Fonte: BRASIL, 2001.

Neste sentido, os projetos pedagógicos de curso passaram a ter mais autonomia em pensar as disciplinas, as quais deveriam prever a formação de competências dos novos profissionais.

Porém, faz-se necessária uma discussão mais crítica sobre as DCNs de forma a perceber em que de fato contribuem para a formação de profissionais que atendam às necessidades da sociedade na qual estão inseridos.

\section{DIRETRIZES CURRICULARES NACIONAIS PARA BIBLIOTECONOMIA: FAVORECIMENTO À FLEXIBILIZAÇÃO DOS CURRÍCULOS}

Nas últimas décadas, as questões afetas à formação de profissionais de diversas áreas passaram por intensas discussões nas searas da administração pública federal no Brasil. Nesse sentido, o Conselho Nacional de Educação (CNE) incluiu nas esferas deliberativas de seu alcance a remodelagem das estruturas curriculares dos cursos de graduação na educação superior. Os objetivos do estabelecimento destas Diretrizes foram a proposição de ênfases e eixos formadores que visavam uma compreensão para além da clássica divisão por área de atuação, considerando um entendimento processual ampliado. No âmbito do CNE, observou-se movimentos claros na direção da consecução de uma maior organicidade para a formação de profissionais das diversas áreas de conhecimento.

Conforme indica o site do Conselho Nacional de Educação, o referido Conselho se configura por ser órgão colegiado integrante do Ministério da Educação e foi instituído pela Lei 9.131 , de 25/11/95, com a finalidade de colaborar na formulação da Política Nacional de Educação e exercer atribuições normativas, deliberativas e de assessoramento ao Ministro da Educação.

O CNE possui duas Câmaras temáticas específicas: a Câmara de Educação Básica e de Educação Superior, que são constituídas cada uma, por doze conselheiros, sendo membros natos em cada Câmara, respectivamente, o Secretário de Educação Fundamental e o Secretário de Educação Superior do Ministério da Educação, nomeados pelo Presidente da República Federativa do Brasil. 
Ainda segundo o sítio na internet do CNE, a Câmara de Educação Superior (CES), organismo de relevância mais direta para este trabalho, teve algumas de suas atribuições alteradas na forma dos arts. 20 e 21 da Medida Provisória 2.216-37, de 31 de agosto de 2001.

Segundo o site do Conselho Nacional de Educação:

Até a edição da Medida Provisória 2.216, a Câmara de Educação Superior deliberava sobre a autorização, o reconhecimento, a renovação de reconhecimento de todos os cursos de graduação das instituições de ensino superior vinculadas ao Sistema Federal de Ensino, sobre o credenciamento de instituições de ensino superior, assim como sobre a aprovação de Estatutos e Regimentos provenientes dessas instituições. A partir da edição Medida Provisória 2.216, e do Decreto 3.860/2001, que a regulamentou, a Câmara de Educação Superior passou a se manifestar somente nos processos relativos aos cursos de Direito e aos da área de saúde (Medicina, Psicologia e Odontologia) e sobre o credenciamento das instituições que pretendem ministrar cursos na área jurídica e da saúde, e sobre o credenciamento e o recredenciamento de Universidades e Centros Universitários, ficando a cargo do próprio MEC a manifestação sobre os demais cursos de graduação e o credenciamento e o recredenciamento das instituições de ensino superior correspondentes. No tocante aos Estatutos e Regimentos, a competência da Câmara restringe-se, hoje, à aprovação dos Estatutos das Universidades e Centros Universitários, enquanto que a aprovação de Regimentos das instituições não universitárias ficou sob a responsabilidade do MEC.

As atribuições da Câmara de Educação Superior foram modificadas pela

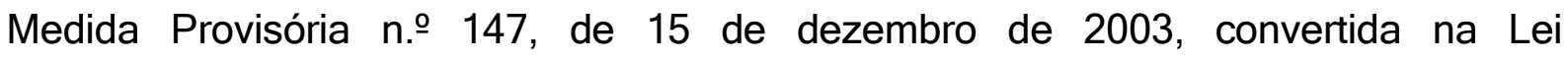
10.861/2004, que institui o Sistema Nacional de Avaliação e Progresso do Ensino Superior e dispõe sobre a avaliação do ensino superior, revoga a alínea "a" do $\S 2^{\circ}$ do art. $9^{\circ}$ da Lei $n^{\circ} 4.024$, de 20 de dezembro de 1961 , e os artigos $3^{\circ}$ e $4^{\circ}$ da Lei $n^{\circ}$ 9.131, de 24 de novembro de 1995, que criou o Conselho Nacional de Educação. (CONSELHO NACIONAL DE EDUCAÇÃO (Brasil), 2016)

É imperativo dizer que as Diretrizes Curriculares Nacionais para os cursos de graduação em Biblioteconomia, objeto central desta seção, foram emitidas pela Câmara de Ensino Superior em momento anterior à reformulação de suas competências. Estas Diretrizes foram homologadas pelo Parecer CNE/CES № 492/2001, publicado no Diário Oficial da União em 9 de julho de 2001, e 
posteriormente retificado pelo parecer no 1363/2001, publicado no Diário Oficial da União em 29/01/2002.

Especificamente sobre as Diretrizes Curriculares Nacionais em questão, tratase de um documento emitido e homologado pelo Conselho Nacional de Educação por meio da Câmara de Educação Superior, que traz como seu assunto principal: "Diretrizes Curriculares Nacionais dos cursos de Filosofia, História, Geografia, Serviço Social, Comunicação Social, Ciências Sociais, Letras, Biblioteconomia, Arquivologia e Museologia." (BRASIL, 2001).

$\mathrm{Na}$ estrutura deste documento os elaboradores fazem uma pequena introdução da área de conhecimento e apresentam em seguida as Diretrizes específicas. Conforme mencionado anteriormente, as Diretrizes se encontram organizadas nos seguintes eixos ou tópicos: Perfil dos Formandos; Competências e Habilidades- Gerais e Específicas; Conteúdos Curriculares; Estágios e Atividades Complementares; Estrutura do Curso e; Avaliação Institucional.

De modo geral, a partir da análise das Diretrizes Curriculares dos cursos de graduação em Biblioteconomia, percebe-se uma patente flexibilização da proposta formativa emanada pelo Conselho Nacional de Educação, uma vez que, embora determine um patamar mínimo de características com relação, por exemplo, ao perfil do egresso, delega às Instituições de Ensino Superior à prerrogativa de acrescer outras vertentes de formação na construção do perfil do aluno concluinte dos cursos de Biblioteconomia.

Ainda sobre a flexibilização proposta pelas Diretrizes Curriculares Nacionais, tem-se a determinação de um conjunto de habilidades e competências que deverão ser fomentadas pelos cursos. Contudo, elas apresentam um caráter amplo e geral, de modo que os cursos dentro de seus próprios contextos podem adaptá-las em conteúdos específicos ministráveis.

No que tange os Conteúdos Curriculares, mais uma vez observam-se aspectos de flexibilidade, uma vez que as Diretrizes apontam para a necessidade de oferecer dois grandes eixos de conteúdos. O primeiro de caráter geral e amplo, externo ao domínio temático da Biblioteconomia visa favorecer o aproveitamento do segundo eixo de conteúdos, de caráter mais específico.

Ponto que merece destaque acerca dos conteúdos curriculares é o fato do CNE recomendar, de modo literal, "que os projetos acadêmicos acentuem a adoção de uma perspectiva humanística na formulação dos conteúdos, conferindo-lhes um 
sentido social e cultural que ultrapasse os aspectos utilitários mais imediatos sugeridos por determinados itens." (Conselho Nacional de Educação, 2001).

No que diz respeito aos três últimos itens das Diretrizes Curriculares- Estágios e Atividades Complementares; Estrutura do Curso e; Avaliação Institucional, o CNE outorga ao Colegiado do curso a responsabilidade de criar normas para orientar a realização destas práticas. Isso garante às instituições um conforto importante na determinação de padrões, critérios e atribuições.

Cabe destacar que aspectos mais formais, por exemplo, definições numéricas de horas/aula; para atividades ou mesmo para duração do curso de graduação não se encontram no escopo das Diretrizes Curriculares Nacionais.

Vale dizer que esse viés amplo e generalista das Diretrizes Curriculares Nacionais não é imune às críticas e oposições. O posicionamento de Vieira (2006) deixa claro que os impactos das reformas curriculares recentes e adoção de diretrizes gerais apontam para uma formação voltada para o mercado de trabalho sob a lógica da competência, qualificação, empregabilidade e profissionalização. Segundo a autora, tais bases não contribuem para uma formação geral de indivíduos críticos, transformadores ou questionadores, mas em contrapartida, volta-se para a formação profissionalizante (VIEIRA, 2006, p. 108)

Outros autores endossam as críticas de Vieira (2006), como o caso de Cattani, Oliveira e Dourado (2001). Os autores revelam que o processo de reestruturação produtiva do capitalismo global oriundos da acumulação flexível e da flexibilização do trabalho apresentou novas questões para o campo da produção do conhecimento e para a formação profissional. Eles indicam que, sob o novo paradigma da produção capitalista, as reformas curriculares dos cursos superiores são diretamente afetadas pelos novos perfis profissionais e modelos de formações exigidos pela lógica da empregabilidade. Duas características passam a ser centrais neste novo perfil profissional: "polivalência e flexibilidade profissional" (CATTANI, OLIVEIRA e DOURADO, 2001, p. 71).

Para Cattani, Oliveira e Dourado (2001), essas medidas visam fomentar a flexibilidade na estruturação dos cursos de graduação, o que contribuiria para a lógica da formação de profissionais mais dinâmicos e adaptáveis às novas demandas do mercado do trabalho. Entretanto, eles chamam a atenção para o fato de que todo esse ideário da flexibilização curricular, assimilado pelos documentos das instâncias executivas responsáveis pela formulação de diretrizes para a graduação no país, 
parece decorrer da compreensão de que estão ocorrendo mudanças no mundo do trabalho e, consequentemente, nos perfis profissionais, o que ocasiona a necessidade de ajustes curriculares nos diferentes cursos de formação profissional. Essas dinâmicas certamente naturalizariam o espaço universitário como campo de formação profissional em detrimento de processos mais amplos, reduzindo, sobretudo, o papel das universidades (CATTANI, OLIVEIRA \& DOURADO 2001, p 75).

Os autores convidam, por fim, para o debate sobre a necessidade do pensamento articulado da função social da educação superior em detrimento de um consumo acrítico de políticas curriculares determinadas e emanadas verticalmente no estilo top-down o que poderia significar em grande parte, a aproximação com os princípios da educação privada mercantil. (CATTANI, OLIVEIRA e DOURADO, 2001, p 75).

Na tentativa da realização de uma reestruturação curricular pensada de forma crítica e inspirada nas Diretrizes do Conselho Nacional de Educação, apresenta-se a seguir o relato de experiência acerca da reestruturação do curso de graduação de Biblioteconomia da Universidade Federal do Rio Grande do Norte como uma proposta de metodologia que poderá ser adotada no futuro por outras Instituições de Ensino Superior observando seus contextos e especificidades.

\section{FORMAÇÃO DO BIBLIOTECÁRIO NO RIO GRANDE DO NORTE}

De acordo com a resolução no 39 de 1996 do CONSEPE-UFRN foi criado o curso de Biblioteconomia da Universidade Federal do Rio Grande do Norte. Segundo relatos de docentes que constituíram o primeiro colegiado do Curso de Biblioteconomia da Universidade Federal do Rio Grande do Norte (UFRN), este foi criado no ano de 1996, no então Departamento de Biblioteconomia, quando contou com a assessoria da Universidade de Brasília (UNB), do Instituto Brasileiro de Informação em Ciência e Tecnologia (IBICT) e também da Pró-reitoria de Graduação da UFRN. Neste sentido, a estrutura curricular foi formada com base no $2^{\circ}$ Currículo Mínimo estabelecido pelo CNE em 1982.

A primeira estrutura curricular do Curso de Biblioteconomia da UFRN data do ano de 1997, com carga horária total de 2.820 horas, sendo 300 horas de componentes curriculares optativos. Conforme estabelecia a legislação da época, as disciplinas dividiam-se em matérias de Formação Geral, Instrumentais e de formação 
profissional. Numa tentativa de visualizar essa correspondência, foi elaborado Quadro 3, comparativo do currículo mínimo e o do curso da UFRN.

QUADRO 3 - Comparativo das matérias do segundo currículo mínimo e o primeiro currículo do Curso de Biblioteconomia da UFRN - matérias obrigatórias

\begin{tabular}{|c|c|c|}
\hline $\begin{array}{l}\text { Tipo de } \\
\text { matéria }\end{array}$ & Currículo Mínimo de 1982 & Currículo da UFRN 1997 \\
\hline $\begin{array}{l}\text { Formação } \\
\text { Geral }\end{array}$ & $\begin{array}{l}\text {-Comunicação; } \\
\text {-Aspectos sociais, políticos } \\
\text { e econômicos do Brasil } \\
\text { Contemporâneo; } \\
\text {-História da Cultura; }\end{array}$ & $\begin{array}{l}\text {-Teoria da Comunicação I; } \\
\text {-História da Arte I; } \\
\text {-História da cultura; } \\
\text {-Cultura brasileira; } \\
\text {-Biblioteconomia e sociedade } \\
\text { brasileira; } \\
\text {-Sociologia I }\end{array}$ \\
\hline mental & $\begin{array}{l}\text {-Lógica; } \\
\text {-Língua portuguesa e } \\
\text { literatura da língua } \\
\text { portuguesa; } \\
\text {-Língua } \\
\text { moderna; } \\
\text {-Métodos e técnicas de } \\
\text { pesquisa; }\end{array}$ & $\begin{array}{l}\text {-Metodologia do Trabalho } \\
\text { Científico; } \\
\text {-Lógica; } \\
\text {-Língua inglesa IX; } \\
\text {-Prática de leitura e produção de } \\
\text { textos I; } \\
\text {-Elementos de Estatística } \\
\text { aplicados a Biblioteconomia; } \\
\text {-Introdução a Administração; } \\
\text {-Organização e métodos; } \\
\text {-Introdução à informática; } \\
\text {-Softwares aplicativos; }\end{array}$ \\
\hline $\begin{array}{l}\text { Formação } \\
\text { Profissional }\end{array}$ & $\begin{array}{l}\text {-Informação aplicada a } \\
\text { Biblioteconomia } \\
\text {-Produção dos registros do } \\
\text { conhecimento; } \\
\text {-Formação e de } \\
\text { desenvolvimento } \\
\text { coleções; }\end{array}$ & $\begin{array}{l}\text {-Introdução à Biblioteconomia e a } \\
\text { Ciência da Informação; } \\
\text {-Estudo de usuário; } \\
\text {-Análise da informação; } \\
\text {-Representação Descritiva I e II; } \\
\text {-Representação Temática I, II e III; } \\
\text {-Editoração; }\end{array}$ \\
\hline
\end{tabular}




\begin{tabular}{|l|lr|l|}
\hline & \multicolumn{2}{|l|}{-Controle bibliográfico dos } & -Controle Bibliográfico \\
& registros do conhecimento; & -Bibliografia geral; \\
& -Disseminação & da & -Planej. de biblioteca e serviço de \\
& informação; & informação; \\
& -Administração & de & -Organização e administração de \\
bibliotecas. & & Bibliotecas e serviços de \\
& informação; \\
& -Formação e desenvolvimento de \\
& coleções; \\
& -Organização de arquivos; \\
& -Serviço de Informação I e II; \\
& -Redes e sistemas de informação. \\
\hline
\end{tabular}

Fonte: Elaborado a partir de dados extraídos do Sistema de Gestão Acadêmica da UFRN (SIGAA) e Almeida; Baptista (2013).

Como já dito anteriormente, a partir de 2001, a formação em Biblioteconomia no Brasil passou a não mais exigir um currículo mínimo. Os currículos deveriam, no entanto, adequar-se as Diretrizes Curriculares Nacionais. Na UFRN essa adequação aconteceu em 2007 e foi implementada em 2008. A nova proposta alterou a carga horária do Curso para 2.880 horas, sendo que a estrutura sofreu readequação de carga horária e aumento de disciplinas. Como forma de perceber as mudanças empreendidas, foi elaborado o Quadro 4 confrontando o primeiro currículo do curso, baseado no currículo mínimo e o segundo currículo, baseado nas diretrizes curriculares nacionais.

Quadro 4 - Mudanças implementadas na estrutura curricular do Curso de Biblioteconomia da UFRN

\begin{tabular}{|l|l|}
\hline $\begin{array}{l}\text { Curso de Biblioteconomia 1997 } \\
\text { Baseado no Currículo Mínimo de } \\
1982\end{array}$ & $\begin{array}{l}\text { Currículo da UFRN 2008 } \\
\text { Baseado nas Diretrizes Curriculares } \\
\text { Nacionais }\end{array}$ \\
\hline -Teoria da Comunicação I; & -Teoria da Comunicação I; \\
\hline -História da Arte I; & -História da Arte I; \\
\hline -História da cultura; & -História da cultura; \\
\hline -Cultura brasileira; & -Cultura brasileira; \\
\hline
\end{tabular}




\begin{tabular}{|c|c|}
\hline $\begin{array}{lll}\text {-Biblioteconomia } & \text { e } & \text { sociedade } \\
\text { brasileira; } & & \end{array}$ & -Biblioteconomia e sociedade brasileira; \\
\hline -Sociologia I & -Sociologia I \\
\hline -Metodologia do Trabalho Científico; & $\begin{array}{l}\text {-Metodologia da Pesquisa em Bibliot. I e } \\
\text { II; }\end{array}$ \\
\hline -Lógica; & -Lógica; \\
\hline -Língua inglesa IX; & -Língua inglesa IX; \\
\hline $\begin{array}{l}\text {-Prática de leitura e produção de } \\
\text { textos I; }\end{array}$ & -Prática de leitura e produção de textos I; \\
\hline $\begin{array}{l}\text {-Elementos de Estatística aplicados } \\
\text { a Biblioteconomia; }\end{array}$ & $\begin{array}{l}\text {-Elementos de Estatística aplicados a } \\
\text { Biblioteconomia; }\end{array}$ \\
\hline -Introdução a Administração; & -Gestão de Pessoas I; \\
\hline -Organização e métodos; & -Organização e processos; \\
\hline -Introdução à informática; & -Introdução à informática; \\
\hline -Softwares aplicativos; & -Softwares aplicativos; \\
\hline $\begin{array}{l}\text {-Introdução à Biblioteconomia e a } \\
\text { Ciência da Informação; }\end{array}$ & $\begin{array}{l}\text {-Fundamentos da Biblioteconomia e } \\
\text { Ciência da Informação; }\end{array}$ \\
\hline -Estudo de usuário; & $\begin{array}{l}\text {-Estudo de usuário em unidades de } \\
\text { informação; }\end{array}$ \\
\hline \multirow[t]{2}{*}{-Análise da informação; } & -Análise da informação; \\
\hline & $\begin{array}{l}\text {-Introd. ao tratamento temático da } \\
\text { Informação; }\end{array}$ \\
\hline -Representação Descritiva I e II; & -Representação Descritiva I, II e III; \\
\hline -Representação Temática I, II e III; & -Representação Temática I, II e III; \\
\hline -Editoração; & -Editoração; \\
\hline -Controle Bibliográfico; & -Registro do Conhecimento; \\
\hline -História do Livro e das Bibliotecas; & -História do Livro e das Bibliotecas; \\
\hline -Bibliografia geral; & -Fontes de informação I e II; \\
\hline $\begin{array}{l}\text {-Planej. de bibliot. e serviço de } \\
\text { informação; }\end{array}$ & $\begin{array}{l}\text {-Planejamento em unidades de } \\
\text { informação; }\end{array}$ \\
\hline -Organização $\quad$ e $\quad$ administ. $\quad$ de & -Gestão de unidades de informação; \\
\hline Bibliotecas e serviços de informação; & -Marketing em unidades de informação; \\
\hline -Formação e desenvolvimento de & -Formação e desenvolvimento de \\
\hline
\end{tabular}




\begin{tabular}{|l|l|}
\hline coleções; & coleções; \\
\hline -Organização de arquivos; & -Gestão documental; \\
\hline -Serviço de Informação I e II; & -Serviço de informação; \\
\hline -Redes e sistemas de informação. & -Redes e serviços de informação I e II; \\
\hline
\end{tabular}

Fonte: Elaborado a partir de dados extraídos do Sistema de Gestão Acadêmica da UFRN (SIGAA)

Disciplinas que tiveram mudança de nome e/ou ementa

Disciplina sem equivalência no currículo anterior

Observando o quadro acima, percebemos que o currículo vigente do curso (em processo de reformulação) ainda apresenta uma forte influência do 20 currículo mínimo do CNE, notadamente no que diz respeito às disciplinas de formação geral e instrumentais, com exceção das disciplinas Introdução à Administração e Organização e Métodos que são elaboradas e ofertadas pelo Departamento de Administração. As mudanças foram empreendidas apenas nas disciplinas de formação técnica as quais foram relativas a mudança de denominação, desmembramento de conteúdo e agrupamento.

Neste contexto, e diante da necessidade de rever a estrutura curricular em vigor, o Núcleo Docente Estruturante do Curso de Biblioteconomia empreendeu um esforço coletivo para pensar e elaborar uma metodologia para reestruturação do Projeto Pedagógico do Curso, conforme descrevemos a seguir.

\subsection{PROPOSTA METODOLÓGICA PARA REESTRUTURAÇÃO DO PROJETO PEDAGÓGICO DO CURSO DE BIBLIOTECONOMIA: A EXPERIÊNCIA DA UFRN}

A partir do entendimento de que vive-se em um momento de mudanças paradigmáticas na área de Biblioteconomia, o binômio - posse e uso da informação ganha um novo contorno. Emerge, portanto, a discussão voltada à formação do bibliotecário enquanto mediador da informação em diferentes espaços. Além disso, há a necessidade de não negligenciar a formação humanista, prerrogativa da profissão, discutir e efetivar uma reestruturação curricular do Projeto Pedagógico do Curso de Biblioteconomia da UFRN, que se mostra urgente e necessária.

Para tanto, o primeiro passo foi refletir sobre as práticas docentes, tomando como base, a estrutura curricular vigente. Dois fatores motivaram fortemente esse repensar. O primeiro deles foi a participação no Fórum "A formação do profissional da 
informação: desafio contemporâneo" que ocorreu em maio de 2014 na Escola de Comunicações e Artes - USP/São Paulo. O objetivo do evento foi discutir temas relacionados à formação do bibliotecário e os possíveis termos de um projeto pedagógico de curso, partilhados entre coordenadores de cursos de Biblioteconomia, docentes, profissionais e alunos.

Como produto final desse fórum, foi divulgada uma Carta Aberta resultante das discussões ocorridas com reflexões sobre os seguintes temas: identificação da produção de conhecimento dos cursos de Biblioteconomia voltada para responder às demandas da sociedade; a participação dos cursos de Biblioteconomia na elaboração de políticas públicas; os cursos de Biblioteconomia e as exigências do mercado de trabalho - público ou privado; causas e superação da alta evasão e baixa procura nos cursos de Biblioteconomia; superação da formação de um bibliotecário genérico; e por fim, importância e o papel de recursos online no ensino da Biblioteconomia como forma de contribuir para a autonomia dos discentes.

A construção da Carta Aberta, com o resultado das discussões de representantes dos cursos de Biblioteconomia de todo o Brasil, possibilitou a percepção de que as preocupações na formação do bibliotecário é um tema comum a todos, independente da região do país e isso motivou repensar o Projeto Pedagógico de Curso, à luz das questões abordadas.

O segundo passo motivador foi a possibilidade eminente da avaliação do curso pelo Ministério da Educação - MEC. Outro fator era a necessidade de uma ampla revisão do PPC, considerando que a última estruturação havia ocorrido em 2007, com ajustes em 2010.

Assim, o NDE solicitou à Pró-reitora de Planejamento e Coordenação Geral da UFRN, apoio para realização de uma auto avaliação, feita pela Comissão Própria de Avaliação - CPA da UFRN. A auto avaliação ocorreu em setembro de 2014 e se deu em dois momentos. No primeiro houve oficinas com professores de Biblioteconomia e dos demais departamentos que lecionavam no curso e, separadamente, oficina com alunos dos diversos períodos de formação (foi recomendado o número máximo de 04 alunos por período).

As oficinas tiveram como documento de referência o Projeto Pedagógico do Curso - PPC, com duração prevista de duas horas de atividades, onde foram coletados dados para o relatório parcial, que seria apresentado na segunda etapa da 
avaliação. As oficinas aconteceram no mesmo dia e horário com membros da CPA coordenando os trabalhos.

$\mathrm{Na}$ segunda etapa, uma semana depois da primeira, ocorreu uma oficina conjunta com professores e alunos. Nessa oficina foram apresentados e discutidos os relatórios das oficinas individuais com os depoimentos dos professores e alunos, destacando as convergências e divergências encontradas. A partir daí, formaram-se pequenos grupos compostos por professores e alunos, para pensarem conjuntamente em propostas para superação de problemas apontados. Após a discussão de todas as questões, elaborou-se um relatório final que posteriormente foi aprovado no colegiado do curso.

Dessa forma, o grupo que compõe o curso de Biblioteconomia da UFRN tinha em mãos dois importantes instrumentos balizadores de suas reflexões: a carta aberta resultado do fórum dos coordenadores de curso, e o relatório final do exercício de auto avaliação do curso, ambos ocorridos em 2014.

Em dezembro de 2014 ocorreu a avaliação do curso pelo INEP - MEC. No entanto, a avaliação se deu ainda com base no Projeto Pedagógico de Curso vigente, sem tempo hábil para ter ocorrido a reforma almejada pelo grupo. Este fato só veio a se iniciar em 2015, com a constituição de comissões de análise das disciplinas, deliberadas pelo Núcleo Docente Estruturante e aprovada em colegiado de curso. Estabeleceu-se como forma de aperfeiçoar o trabalho, a divisão dos professores a partir das áreas estabelecidas nas Diretrizes Curriculares Nacionais: Fundamentos Teóricos da Biblioteconomia e da Ciência da Informação; Organização e Tratamento da Informação; Recursos e Serviços de Informação e Gestão de Unidades de Informação.

Foi necessário um trabalho extenso e intensivo de análise das disciplinas em relação ao seu título, ementa e objetivos à luz das questões discutidas no ano de 2014. Os grupos, divididos por áreas, trabalharam durante todo o ano de $2015 \mathrm{com}$ a análise das disciplinas, chegando a montagem de um novo fluxograma, com as adequações julgadas necessárias. Ao final de todas as discussões separadas por áreas, o grupo se reuniu e montou o novo fluxograma, fruto das discussões (onde além da análise da disciplina, cabia a sugestão de mudança de semestre no fluxograma).

Como forma de melhor visualização e análise do novo fluxograma, foi elaborada a montagem dos semestres com "post-it" de diversas cores, onde cada cor 
correspondia a uma área. Utilizou-se uma grande mesa de apoio para possibilitar a visualização do desenrolar de cada semestre e distribuir harmoniosamente as disciplinas sem sobrecarregar nenhuma área específica, nem desestruturar a formação do aluno.

A seguir serão apresentados os fluxogramas das disciplinas no currículo vigente e na proposição do grupo. (Figuras 1 e 2).

Figura 1 - Fluxograma das disciplinas do Curso de Biblioteconomia (PPC 2007)

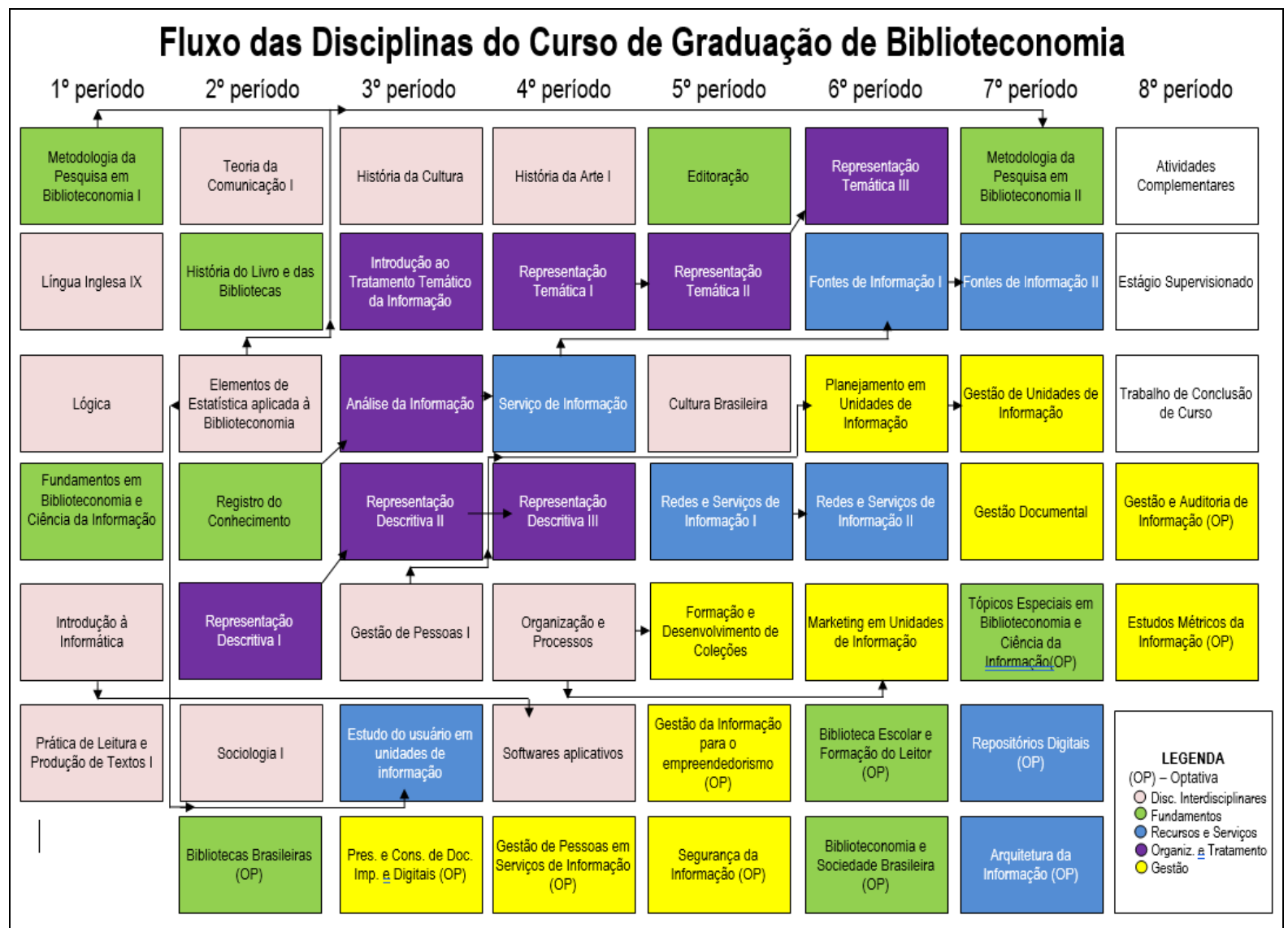

Fonte: Baseado no PPC do Curso de Biblioteconomia da UFRN (2007) 
Figura 2 - Proposta de novo Fluxograma para o PPC do Curso de Biblioteconomia da UFRN

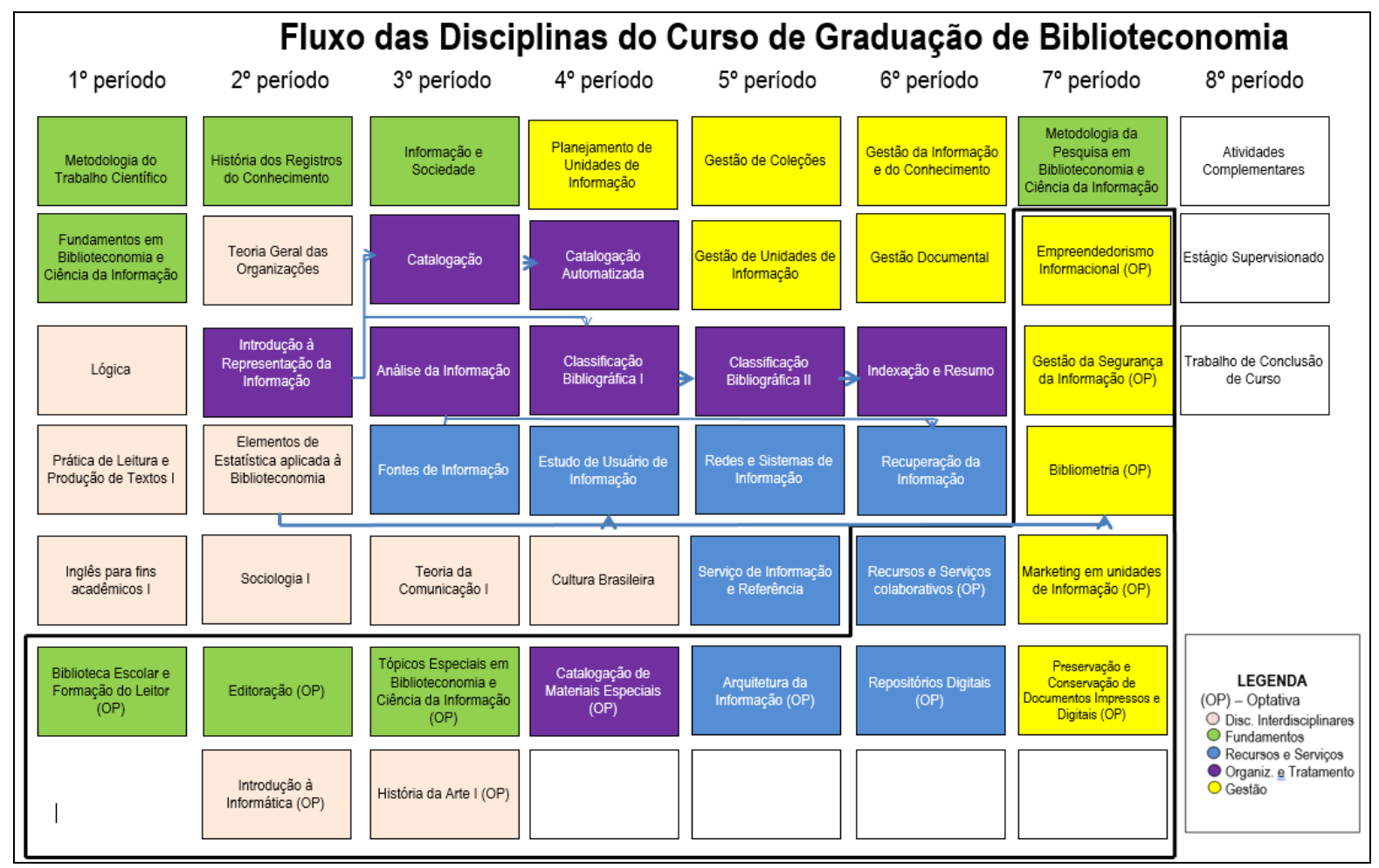

Fonte: NDE Biblioteconomia UFRN

O exercício de (re) pensar a respeito de práticas já enrijecidas é árduo, porém necessário. O que se pensou a respeito de calendário para o término das discussões, foi revisto e estendido porque entendeu-se que a maturação para determinadas questões era necessária. Porém, a urgência de uma nova estrutura curricular nos motivou a continuar sem perder o foco das questões principais.

Outra vertente, complementar às disciplinas eram as atividades complementares obrigatórias, especificamente: estágio curricular obrigatório; trabalho de conclusão de curso e outras atividades, todas estabelecidas através de resoluções. Para a análise e discussão dessas resoluções, o grupo decidiu que todos os docentes participariam das discussões, sem as divisões por áreas e sempre com 0 compromisso de adaptá-las às necessidades de um novo contexto de atuação. Essas atividades ocorreram durante o semestre 2016.1 e a implantação da nova estrutura curricular do curso de graduação em Biblioteconomia está prevista para o semestre de 2016.2 .

A experiência de trabalhar conjuntamente com quase todos os docentes do curso de Biblioteconomia da UFRN em prol de um objetivo único, trouxe segurança para enfrentar os desafios que surgiam (dúvidas, angústias, cansaço, ausências etc.). 
Entende-se que o grupo saiu fortalecido e consciente da necessidade de períodos menores de reanálise de suas ações. Para tanto, estabeleceu-se um período de revisão do Projeto Pedagógico do Curso a cada três anos, juntamente com o Plano Trienal do Departamento de Ciência da Informação.

Espera-se que a incorporação de ações provenientes dos acontecimentos prévios a reestruturação do PPC, sobretudo a introspecção da importância de um trabalho "conjunto e harmônico" (FÓRUM, 2014) dos docentes, favorecerá grandemente a qualidade do nosso curso.

\section{CONSIDERAÇÕES FINAIS}

Apresentou-se neste artigo os processos reflexivos empreendidos pelo Núcleo Docente Estruturante (NDE) do Curso de Biblioteconomia da UFRN, acerca da reformulação do Projeto Pedagógico do Curso (PPC), no que diz respeito à estrutura curricular.

Percebeu-se que a formação do Bibliotecário no Brasil é relativamente jovem e fortemente marcada por influências estrangeiras, europeias e norte-americanas, as quais se cristalizaram nos currículos mínimos brasileiros. Essa influência amplamente difundida norteou a formação deste profissional durante todo o século XX.

A adoção de forma acrítica desta perspectiva exógena apresenta-se na literatura como sendo um fenômeno mobilizador de intensos debates e antagonismos, isso porque tal ocorrência contribuía para a formação de bibliotecários desconectados com o multifacetado contexto brasileiro, em suas dimensões políticas, sociais e econômicas.

Neste sentido, num projeto de mudança, a estrutura federativa nacional por meio do Conselho Nacional de Educação estabeleceu uma nova estruturação para os cursos de nível superior com objetivo de ampliar as possibilidades de adequação e atualização frente aos contextos em que os cursos fossem ofertados. Isso através do estabelecimento de competências e habilidades requeridas ao perfil do egresso o que conferia maior autonomia e flexibilidade aos cursos e universidades.

A realidade da formação do Bibliotecário no Rio Grande do Norte é influenciada diretamente pelas mudanças no contexto educacional nacional. Isso porque, no momento da fundação do curso de Graduação em Biblioteconomia em 1996 a estrutura curricular refletia o que apregoava o currículo mínimo vigente naquele 
momento. Posteriormente, ao passar por uma reestruturação, no ano de 2007, o Colegiado de Graduação em Biblioteconomia da UFRN empreendeu esforços na tentativa de adequar a estrutura curricular às novas Diretrizes Nacionais.

Quando observados de modo comparativo, ambos os currículos, percebe-se que as mudanças ensejadas não se configuraram como significativas, na medida em que uma parte considerável dos componentes curriculares de 1996 foram transportados de forma integral ou parcial para a estrutura de 2007.

Essa constatação serviu de inspiração para discussões e posicionamentos mais críticos e reflexivos diante das decisões a serem tomadas para a elaboração da nova proposta curricular do Curso de Biblioteconomia da UFRN.

Em função do contexto observado, o Núcleo Docente Estruturante estabeleceu uma metodologia coletiva e sistemática que promovesse debates, consensos e deliberações por parte dos docentes através das áreas de conhecimento estabelecidas pelas Diretrizes Curriculares Nacionais. Por ainda estar em andamento, esses debates favorecem, em grande medida, uma ampla compreensão dos contextos que envolvem as competências e habilidades, cerne das Diretrizes Nacionais, e sua inserção nos conteúdos programáticos das disciplinas de forma coerente e objetiva.

Desta forma, a metodologia utilizada para pensar a nova estrutura curricular resultou numa melhor articulação entre os conteúdos ministrados nas diferentes áreas de formação tendo como fios condutores as competências e habilidades. Essa nova perspectiva, tende a diminuir os distanciamentos teóricos e práticos entre as áreas de conhecimento na formação do Bibliotecário, superando vícios e engessamentos remanescentes dos currículos mínimos.

Percebeu-se, enfim, que a discussão sobre formação do Bibliotecário no Brasil necessita de um olhar permanente dos cursos, com momentos de reflexão sobre questões teóricas, que tragam contribuição para os ajustes necessários, de forma periódica.

\section{REFERÊNCIAS}

ALMEIDA, N. B. F. de; BAPTISTA, S. G. Breve histórico da Biblioteconomia brasileira: formação do profissional. In: CONGRESSO BRASILEIRO DE BIBLIOTECONOMIA, DOCUMENTO E ClêNCIA DA INFORMAÇÃO, 25., 2013, Florianópolis. Anais...Florianópolis: Febab, 2013. p.1 - 13. Disponível em: <https://portal.febab.org.br/anais/article/view/1508>. Acesso em: 20 maio 2016. 
BRASIL. Parecer no 492, de 9 de julho de 2001. Diretrizes Curriculares Nacionais dos cursos de Filosofia, História, Geografia, Serviço Social, Comunicação Social, Ciências Sociais, Letras, Biblioteconomia, Arquivologia e Museologia. Parecer CNE/CES. Brasília, DF, 9 jul. 2001. Seção 1, p. 50.

CASTRO, C. História da Biblioteconomia brasileira. Brasília: Thesaurus, 2000.

CATANI, Afrânio M.; OLIVEIRA, João F.; DOURADO, Luiz F. Política educacional, mudanças no mundo do trabalho e reforma curricular dos cursos de graduação no Brasil. Educação \& Sociedade, Campinas, v. 22, n. 75, p. 67-83, 2001.

CONSELHO NACIONAL DE EDUCAÇÃO (Brasil). Ministério da Educação. Conselho Nacional de Educação: apresentação. 2016. Disponível em: <http://portal.mec.gov.br/conselho-nacional-de-educacao/apresentacao>. Acesso em: 02 maio 2016.

FÓRUM A FORMAÇÃO DO PROFISSIONAL DA INFORMAÇÃO: desafios contemporâneos, 2014, São Paulo. Carta aberta...São Paulo, 2014. Disponível em: < http://www.abrainfo.org.br/noticia/carta-aberta-forum-formacao-do-profissional-dainformacao> Acesso em: 16 maio 2016.

MOREIRA, L. Mapeamento e análise do mercado de trabalho dos egressos do Curso de Biblioteconomia da Universidade Federal do Rio Grande do Norte. In:

ENCONTRO NACIONAL DE PESQUISA EM CIÊNCIA DA INFORMAÇÃO, 16., 2015, João Pessoa. Anais... João Pessoa: Ancib, 2015. p.01 - 06. Disponível em: <http://www.ufpb.br/evento/lti/ocs/index.php/enancib2015/enancib2015/paper/viewFil e/3169 /1069>. Acesso em: 20 maio 2016

MUELLER, S. P.M. Avaliação do estado da arte da formação em Biblioteconomia e ciência da informação. Ci. Inf., v.17, n.1, p.71-81, jan./jun. 1988.

OLIVEIRA, M.; CARVALHO, G. F.; SOUZA, G. T. Trajetória histórica do ensino da biblioteconomia no Brasil. Informação e Sociedade: estudos, João Pessoa, v.19, n.3, p.13-24, dez. 2009. Semestral. Disponível em:

<http://www.ies.ufpb.br/ojs/index.php/ies/article/view/3754/3167>. Acesso em: 10 maio 2016.

SOUZA, F. das C. de. Formação de Bibliotecários para uma sociedade livre.

Encontros Bibli: Revista de Biblioteconomia em Ciência da Informação, Florianópolis, v.11, n.6, p.39-51, jun. 2001. Semestral. Disponível em: . Acesso em: 01 maio 2016

SOUZA, F. das C. de. O ensino da Biblioteconomia no contexto brasileiro. Florianópolis: 1990.

SOUZA, F. de A. das C. de. A contribuição da ABEBD para a configuração política e ideológica das Diretrizes Curriculares Nacionais [DCN] do Curso de graduação em Biblioteconomia implantadas a partir de 2001. Florianópolis: Ufsc, 2012. 44p. Disponível em: <http://eprints.rclis.org/19807/>. Acesso em: 10 maio 2016 
VIEIRA, Ana C. N. C. A política curricular da Educação profissional: os discursos da competência e da empregabilidade. Temas em Educação, João Pessoa, v. 15, n. 1, p. 107-119, 2006. 